$\mathrm{ON}-\mathrm{CHO} \mathrm{NG}$

\title{
INTRODUCTION: \\ REHEARSING THE OLD AND ANTICIPATING \\ THE NEW
}

As with all classics that have long been valued as a fertile fount of wisdom and rich repository of knowledge, the Yijing 《易经》still bemuses and beguiles. Offering a graphically vivid and conceptually dynamic dramaturgy of the ways in which the natural world works in conjunction with the human one, its cosmological architectonics and philosophical worldview continue to have enormous purchase on our current imagination. In the modern and postmodern marketplaces of ideas, the Yijing is sold, bought, and used in diverse ways, ranging from being the textual site of academic hermeneutical excavations to the imagined theater where New Age spiritualism enacts its psychological drama. It is variously a book of moral-ethical pondering, a manual of divination, and a treatise of cosmological musing. As such, it is embraced and discussed in terms of philosophy, religion, psychology, medicine, science, ecology, mathematics, and so on.

But whereas readerly imperatives and responses have no doubt rendered the Classic into a text of multiple significances catering to the needs and sensibilities of pluralistic readerships and clienteles, some original authorly visions and insights remain intact, serving as the cornerstone and point of departure for a wide variety of readings. It is precisely from these very persistent visions and insights, which provide cogent intimations of reality, that the Yijing derives its value and importance: to wit, its classical status. Their apparent truthfulness to our cosmic and human conditions inspires philosophical and even theological questions by speaking to our instinctive belief that the world conforms itself to a dynamic ideal that is nonetheless characterized and defined by change. Regardless of the heterogeneous

ON-CHO NG, Professor, Department of History, Pennsylvania State University; Associate Editor and Book Review Editor, Journal of Chinese Philosophy. Specialties: Confucian hermeneutics and historiography, Late-Imperial Chinese intellectual history. E-mail: oxn1@psu.edu

An important note about the style and format of this supplement issue: Since the various articles, except the preface, introduction, and bibliography, are reprints, we have decided to republish them without altering their original style and format. The only change is the Romanization of Chinese terms, replacing the old Wade-Giles system with the Pinyin one. Future contributors to our Journal should not use this issue as the guide and model.

Journal of Chinese Philosophy, Supplement to Volume 36 (2009) 3-10

(C) 2009 Journal of Chinese Philosophy 
readerly perspectives, the Yijing's authorial designs of the eight trigrams and hexagrams, together with the yin-yang forces and the dao that is constituted thereof, are taken for granted as the integers in a grand universal equation, factored out to represent a ceaselessly changing but stable cosmos in which heaven, earth, and humanity commingle. These symbols represent microcosms of the myriad things, encapsulating the primordial or germinal states of homocosmic phenomena and situations. While the trigram and hexagram are each conceived to be independent and autonomous, their individuation is inextricably tied to one another's being and becoming. This interaction, being both dialectic and synthetic, and diachronic and synchronic, engenders the continuum of change, which is, it goes without saying, the central concept of the Yijing.

We need not rehash here the well-worn and well-known subject of the originating etymology and fundamental definition of the title of $Y i$, except to remind ourselves in an inclusive, ecumenical, and accommodative manner that it possesses three commonly accepted and interrelated meanings that can be corroborated by textual evidence: simplicity, ease, and easiness in the sense of jianyi 简易; change, flux, and transformation with reference to bianyi 变易; and constancy, recurrence, and changelessness in terms of buyi 不易. In short, $y i$ is the creative way of the perpetuity and eternality of change that is simple, easy, and natural, to the extent that the effortless and ceaseless phenomena of multifarious transformations are simultaneously instantiations and substantiations of the unchanging principle of the inevitability of change. Within this armature of mutually penetrating processes and circumstances-constancy and change, being and becoming, being and nonbeing, growth and senescence-the Yijing generates paradigmatic ways of conceiving and perceiving the metaphysical principles and operations of the universe, which since antiquity, have inserted enormous influence on the development of Chinese thought. It is no exaggeration to claim that the Yijing has been for two millennia the Ur-classic for most Chinese thinkers, insofar as it encapsulates the major orientations, dominant motifs, and principal patterns of the Chinese way of thinking about reality. Thus, to delve into this classic is to get at the quintessential and seminal Chinese understanding of the cosmology of nature and the anthropology of humanity. But it is also to discover how such understanding furnishes and serves as the foundational categories and basic assumptions for later philosophical contemplations and metaphysical speculations.

Accordingly, this assemblage of articles previously published in the Journal of Chinese Philosophy conveniently and strategically brings together some of the trenchant interpretations and analyses of the salient, structural aspects of the philosophy of the Yijing. These works 
also reveal how the ancient classic proffers the master philosophical script into which later plots and characters are written. In the lead article, "On Harmony as Transformation: Paradigms from the Yijing," Chung-ying Cheng explores the notion and phenomenon of harmony, or he 和, and philosophically parses its meaning, significance, and import with special reference to the Yijing. To establish an intellectual context for a deep and theoretical understanding of he, Cheng ranges widely by first looking at its various iterations and expressions in the Analects (Lunyu《論語》), Mencius (Mengzi《孟子》), Daodejing 《道德經》, and Zhongyong 《中庸》, and its multidimensional relations to the notionally cognate concepts of tong 同, $y i$ 一, zhong 中, and $y i$ 异. He also compares and contrasts the Chinese notion of he with the Greek, specifically Heraclitus's, notion of harmonia. This scrutiny of the various modes and modalities of harmony lays the ground for Cheng's theorization of $h e$ as it is conceived in the Yijing. He identifies in this classical text a special "ontology of harmony" and "dialectics of harmonization." Such concept of harmony presumes the existence of opposites (and differences, disagreements, and strifes), but instead of destroying the whole, these oppositions contribute to and constitute unity, as eloquently evidenced by the primary ontological duality of yin 陰 and yang 陽. In the yin-yang 陰陽 paradigmatic relation, we see the coexistence of opposition and complementarity as creative transformation. Harmony, as the unity of opposites, is not only an astute descriptive observation of how things work based on experience but also a perspicacious prescriptive principle of explanation that reveals how things come to be. Thus by way of the Yijing, Cheng gives us a theory of harmony, which is also a theory of creative change and transformation through the productive relations between unity and opposites. It is simultaneously the "principle of integration," according to which opposites cohere and unite, and the "principle of differentiation," according to which unity disintegrates and dissolves into opposites. In short, Cheng shows us how a faithful but yet creative reading of an ancient classical text helps to construct a contemporary comprehensive theory of harmony, and therefore also of transformation, change and creativity, which is grounded on a persuasive metaphysics of unity-as-opposites, or opposites-in-unity.

The piece by the late Jesse Fleming, "A Set Theory Analysis of the Logic of the Yijing 《易經》," seeks to pinpoint the major philosophical categories in the Yijing, which, as the author correctly avers, recur time and again in much of later Chinese thought. But the concept of category itself can be problematic when it is applied to the Chinese construal of reality. A category may be ontological if it pertains to the question of being, as in the case of Aristotelian categories of reality. It can be a logical one if it concerns thinking, as with Kantian forms of 
thought. In an effort to define and clarify the kinds of categories discernible in the Yijing, Fleming proposes the use of the notion of "onto-hermeneutic categories" that encompass both the ontological and logico-linguistic elements of categories. Inspired by and elaborating on Chung-ying Cheng's earlier work on the "polaristic principle" of the Yijing, Fleming posits "integration" ( $h e$ 和) and "differentiation" (fen 分) as the two fundamental "metacategories" or "ontohermeneutic categories," that is, higher-order categories that are applied to other categories, in terms of which the multiplicity of concept words in the Yijing, such as dao 道, tian 天, di 地, and jen 人, together with the sixty-four hexagrams, may be interpreted and understood. These two categories enable Fleming's construction of an orderly structural system out of the metaphysics and cosmology of the Yijing, such that the binary or polarized categories (e.g., yin/yang and change/constancy) are shown to be intrinsically related to one another. Integration and differentiation, as onto-hermeneutic categories, bring to light the dialectical nature of the Yijing's mapping of all possible situations through the hexagrams. In contradistinction to standard Western logic, yin and yang and the hexagrams show that integration and differentiation are not mutually exclusive, so much so that change presumes constancy, difference implies identity, part connotes whole. If nothing else, such dynamic and dialectical thinking reminds us that the contemporary fixation on deconstruction, difference, decentering, and particularity may be unreasonably blind to their complementary counterparts of construction, consensus, centering, and universality.

Peter Hershock's "The Structure of Change in the Yijing" proposes another reading of the Yijing that highlights the coherent cosmic order that the ancient text purports to convey. He does so by reordering the hexagrams in an effort to throw into sharp relief the structure of change inherent in them. Hershock's reordering is based on four operationally definable dimensions of change discernable in the Yijing's phenomenology of change: opposition, reversion, transposition, and linking. These dimensions embodied in the hexagrams show that change is a unity of diversity and interdependence, and this morphology of change demonstrates that the world map of the Yijing is isomorphic with the actual world. In other words, the hexagrams that makeup an imagined world order represent no fixed information or inanimate data, that is, a set and codified corpus of knowledge about the reality. Rather, they are heuristic designs and categories that facilitate understanding and instigate reflection as one seeks to cultivate, perfect, and realize oneself by being fully in accord with heaven, earth, and humanity. The world of the hexagrams is one in which the observer must play active and consequential roles, unlike the world found in Newtonian physics in which truth is objectively derived, independent of the observer. Thus, the 
divinatory aspects of the Yijing rest not on divulging future facts and happenings but on providing guidance to actions and thoughts in a constellation of constantly evolving sets of circumstances. In brief, the unity of the hexagrams may be viewed as a mandala that points to the unity of heaven and humanity, wherein individuals endeavor to achieve flourishing by realizing their own nature through acting in concert with a living and changing universe.

Chung-ying Cheng's " $L i$ and $Q i$ in the Yijing: A Reconsideration of Being and Nonbeing in Chinese Philosophy" takes us into the domain of philosophical history by pondering the ways in which the Yijing proffers the conceptual resources for the later development of the li-qi 理气 metaphysical scheme that predominates in the Neo-Confucian tradition. At the same time, Cheng warns us of the perils of reading the Yijing through the Neo-Confucian lenses worn by Zhu Xi 朱喜 and others. Thus, his project is also very much a philosophical exercise that critiques the besetting difficulties and problems in the Neo-Confucian li-qi thinking on account of its stark dualism-li/qi, daoxin/renxin 道心/人心, tianli/qizhi 天理/气质一which unduly and erroneously emphasizes the ontological and axiological differences between the two metaphysical entities. By harking back to the original insights of the Yijing, Cheng reexamines the categories of $l i$ and $q i$ in terms of their reconciliation and unity by reevaluating the creativity of $q i$, showing that $l i$ is a "property" and "end product" of $q i$. To the extent that $l i$ is the "ordering activity" that manifests the creative $q i$, the two cannot be perceived and conceived as separate. Cheng brings this interpretation to bear on the related big question of being (you 有) and nonbeing ( $w u$ 无), asserting that the former is the creative movement $q i$ while the latter the "unlimited source energy of $q i$." In the process, Cheng reveals the critical fact that the Yijing revels in the idea of the co-creativity of being and nonbeing and therefore does not subscribe to the absolute sense of reality in the Western philosophic traditions, which presume the presence of an absolute, immutable being behind all surface phenomena.

Whalen Lai's “The Yijing and the Formation of the Huayan 華嚴 Philosophy" illustrates yet another case of the enormous influence of the Yijing by examining the ways Fazang 法藏, the key patriarch of the Huayan school of Buddhism, appropriated ideas from the ancient Chinese text, especially with specific regard to the concept of "Suchness vasana," that is, the perfumation of avidya, or ignorance, by the Buddhist Absolute of Suchness. Lai embarks on a detailed reading of Fazang's commentary on the scriptural text of Awakening of Faith in Mahayana (Dacheng Qixin Lun 大乘起信论), showing how the Buddhist master, in advancing his thesis of "Dynamic Suchness," expounds on the interaction of the two primordial forces of Suchness 
and Ignorance in light of the Yijing's yin-yang scheme. Notably, Fazang imbues the original Indic Mahayana conception of Suchness, which is unchangingly and inertly absolute, with dynamism and creativity, such that it interacts actively with Ignorance, which, while having its quality of emptiness and nonsubstance, similarly functions actively in the affairs of the world. Just as yin and yang interpenetrate and mutually reinforce to yield a changing dao, so too Suchness is not passive but is vigorously engaged with Ignorance through the process of perfumation, opposing the deluded defilements of consciousness by revealing its virtue and power. Suchness, as the $l i$, or Principle, being in congress with all phenomena and being identified with them, does not merely support the world but in fact actively creates it. In this sense, Suchness is immanent and not some transcendent authority as the repository of pure possibilities truths.

If Whalen Lai's piece concerns intracultural interaction between Sinitic Buddhism and Yijing thinking, then Andreas Schöter's "Flowers and Steps in the Boolean Lattice of Hexagrams" is an explicit cross-cultural exercise of comparison and speculation. It excavates and interrogates the deep structure of the Yijing in terms of Boolean algebra, especially its Lattice theory, which serves as a useful unifying framework of analysis of the different mathematical formulations of the hexagrams, primarily because it provides a way of arranging the figures, which represent the relative amounts of, and the structural distribution of, the yin and yang forces. Schöter examines and parses the works of three contemporary writers on the YijingEdward Hacker's theory of "Hexagram Flowers," Mondo Secter's notion of "Transition Hexagrams," and Stephen Karcher's "Steps of Change." These are all independent and individual attempts at deconstructing the complex circumstances represented by the multiple hexagram lines and their combinations, so as to arrive at a comprehensive and systematic analytical method of reading. Nevertheless, Schöter argues that even though these varied graphic, symbolic, and semiotic interpretations are separate and can be seen in their own light, they can be coherently subsumed in the interpretational schema of Boolean algebra. Such is the case because the Yijing, with its binary representation, has a natural structure that conforms to Boolean algebraic principles. Schöter's essay confirms and illustrates in a novel way the contemporary resonance and significance of the ancient classic as mathematical architectonics.

Linyu Gu's "Time as Emotion versus Time as Moralization: Whitehead and the Yi Jing" conducts comparative analysis from a different perspective. It subjects Alfred North Whitehead's process metaphysics to critical analysis by summoning her understanding of the Yijing's insights into the social, cultural, emotional, and ultimately moral 
dimensions of time. Gu takes pains to demonstrate that Whitehead's conception of humanity's primordial experience of, and confrontation with, time as emotional harmony of physical and mental worlds is in general consonant with the Yijing's construal of shi 时 (time) as shengsheng 生生(ceaseless creativity). Both Whitehead and the Yijing regard creativity as a continuous process and unraveling phenomenon, which is a unitary and harmonious phase and state of physical and conceptual experience. But what is missing in Whitehead's world of "concrescence," wherein "actual occasions" harmoniously grow, unfold, and develop in the plenitude of emotion, is the explicit and direct call for human self-cultivation that eventuates in selftransformation. Humanity, while acknowledged as being integrally a part of an organismic universe, is not recognized as a creative, moral agent. On the other hand, the Yijing cosmology presumes the ontological fact of tianren heyi 天人合一, the realization of which is ensured by humanity's creative effort of ziqiang 自強 (selfcultivation). Gu's analysis throws into sharp relief the fundamental difference between Whitehead's theory of organismic creativity that gives short shrift to human agency and the Yijing's humanistic worldview that holistically conceives of the mutual reinforcement and interpenetration between unceasing human self-cultivation and ceaseless changes in enveloping realities, including the cosmos. Gu thus reveals fruitful ways in which the ancient Chinese Classic of Changes may help us understand, in a complementary manner, a Western metaphysics of change.

The admirable articles selected for republication here no doubt rehearse our understanding of the Yijing and hopefully provoke new ideas and interpretation. But they represent only a handful among many others works that have appeared in recent years. It seems therefore highly useful to take stock of the advances in Yijing studies by including a bibliography consisting of selected works on the ancient classic that have appeared since 1985 . Ably and diligently compiled by Richard Smith, it promises to serve usefully as a valuable, if not indispensable, research tool.

In sum, the various articles collected here, despite their separate topics, varying orientations, and differing foci, all in some major manner point to the central insight of the Yijing that unity presumes opposites and that differences yield identity; and hence, by the way, the title of this supplementary volume, "Philosophy of the $Y i$ 易: Unity and Dialectics," which is also a reference to the central thesis of the first article by Chung-ying Cheng. The universe, as conceived in the Yijing, is a dynamic one propelled by the dialectics of yin and yang, which are not externally observable laws to which humanity merely conform but are the very workings of the universe that human beings 
live and realize. Thus, the Yijing, in our contemporary world, continues to inspire. It redeems us from the sterile scientific worldview that magnifies our insignificant smallness in the cosmos-a mere speck in geological time, a sheer conglomeration of minute atomic activities. It argues against the constricting theistic assertion that human actions, achievements, and even grandeur, are God-bestowed. The Yijing's intricate hexagrams continue to figure and configure for us a cosmos that features the centrality of humanity; its philosophy persists as the voice of a robust humanism. 